\title{
A New Model Rat with Acute Bronchiolitis and Its Application to Research on the Toxicology of Inhaled Particulate Matter
}

\author{
Hiroko KYONO ${ }^{1 *}$, Fumio SERITA ${ }^{1}$, Tadao TOYA ${ }^{1}$, Hisayo KUBOTA ${ }^{1}$, Heihachiro ARITO ${ }^{1}$, \\ Masaya TAKAHASHI ${ }^{1}$, Ryoko MARUYAMA ${ }^{1}$, Katsunori HOMMA ${ }^{1}$, Hisayoshi OHTA ${ }^{2}$, \\ Yoji YAMAUCHI ${ }^{2}$, Minoru NAKAKITA ${ }^{2}$, Yukio SEKI ${ }^{2}$, Yoko ISHIHARA ${ }^{3}$ and Jun KAGAWA ${ }^{3}$ \\ ${ }^{1}$ National Institute of Industrial Health, 21-1, Nagao 6-Chome, Tama-ku, Kawasaki 214-8585, Japan \\ ${ }^{2}$ School of Allied Health Sciences, Kitasato University, Kitasato, Sagamihara 228-8555, Japan \\ ${ }^{3}$ Department of Hygiene \& Public Health (I), Tokyo Women's Medical University, Shinjuku, Tokyo 162-8666, \\ Japan
}

Received September 7, 1998 and accepted November 12, 1998

\begin{abstract}
The aim of the present study was to establish a useful animal model that simulates humans sensitive to inhaled particulate matter (PM). We have developed a new rat model of acute bronchiolitis (Br) by exposuring animals to $\mathrm{NiCl}_{2}(\mathrm{Ni})$ aerosols for five days. Three days following the $\mathrm{Ni}$ exposure, the animals developed signs of tachypnea, mucous hypersecretion, and bronchiolar inflammation which seemed to progress quickly during the fourth to fifth day. They recovered from lesions after four weeks in clean air. To assess the sensitivity of the Br rats to inhaled particles, two kinds of PM of respirable size were tested with doses similar to or a little higher to the recommended threshold limit values (TLVs) for the working environment in Japan. Titanium dioxide $\left(\mathrm{TiO}_{2}=\mathbf{T i}\right)$ was chosen as an inert and insoluble particles and vanadium pentoxide $\left(\mathrm{V}_{2} \mathrm{O}_{5}=\mathrm{V}\right)$, as a representative soluble and toxic airborne material. The Br rats exposed to either $\mathrm{Ti}$ or $\mathrm{V}$ were compared the pathological changes in the lungs and the clearance of particles to those in normal control or Br rats kept in clean aiir. The following significant differences were observed in Br rats: 1. delayed recovery from preexisting lesions or exacerbated inflammation, 2 . reductions in deposition and clearance rate of inhaled particles with the progress of lesions. The present results suggest that $\mathrm{Br}$ rats are more susceptible to inhaled particles than control rats. Therefore, concentrations of particulate matter lower than the TLVs for Japan, which have no harmful effects on normal lungs, may not always be safe in the case of pre-existing lung inflammation.
\end{abstract}

Key words: Bronchiolitic Rats, Exposure to $\mathrm{NiCl}_{2}, \mathrm{TiO}_{2}, \mathrm{~V}_{2} \mathrm{O}_{5}$, Susceptible to Particulate Matter

\section{Introduction}

Although the degree of air pollution has been significantly reduced since the 1970s, new arguments have been raised whether inhalation of any particulate matter (PM) at concentration levels of current $\mathrm{PM}_{10}$ standards in the United

*To whom correspondence and reprint should be addressed.
States relates to the increase of daily mortality ${ }^{1,2)}$. In 1997 , the new $\mathrm{PM}_{2.5}$ standards has been promulgated ${ }^{3)}$, however, the recent workshop summary showed that there is still no clear linkage for any PM size or chemical constituent that extends from source of pollutant to the production of health effects ${ }^{4}$. Presently, not all human but some susceptible groups, such as the elderly, with chronic obstructive pulmonary disease (COPD), asthma and cardiovascular 
Table 1. Experimental design and sampling time after Ni and/or Ti exposure

\begin{tabular}{|c|c|c|c|c|c|c|c|c|c|}
\hline \multirow[b]{2}{*}{ Group Day } & \multicolumn{2}{|c|}{ Exposed to } & \multicolumn{7}{|c|}{ Days after Ti Exposure } \\
\hline & D1-D5 & D6-D10 & D0 & D1 & D3 & D7 & D14 & D28 & D56 \\
\hline CC: normal & Air & Air & $\mathrm{CC}-0$ & $\mathrm{CC}-1$ & $\mathrm{CC}-3$ & $\mathrm{CC}-7$ & CC-14 & CC-28 & \\
\hline CT: normal + Ti & Air & $\mathrm{TiO}_{2}$ & CT-0 & CT-1 & CT-3 & CT-7 & CT-14 & CT-28 & CT-56 \\
\hline BC: $\mathrm{Br}+\mathrm{Air}$ & $\mathrm{Ni}$ & Air & BC-0 & BC-1 & BC-3 & BC-7 & BC-14 & BC-28 & \\
\hline BT: $\mathrm{Br}+\mathrm{Ti}$ & $\mathrm{Ni}$ & $\mathrm{TiO}_{2}$ & BT-0 & BT-1 & BT-3 & BT-7 & BT-14 & BT-28 & BT-56 \\
\hline
\end{tabular}

Daily exposure time was 10:00 a.m. to 15:00 p.m. D0: sampled just after the last exposure. $\mathrm{N}=5 /$ group.

disease are thought to be the target for receiving harmful effects from exposure to PM. In a broad-based approach to studying health effects of environmental particles, one of the recommended strategy to focus on the mechanistic analysis is to employ an animal model, since human exposure has a strict limitation for both ethical and technical reasons. However, only a few animal models have been established with respiratory diseases appropriate to assess the health effects of inhaled PM.

Turning this viewpoint to the working environments, the problem is more serious, since the recommended threshold limit values (TLVs) in the working places are at least one to two order of magnitude higher than in urbane air, and these values are adopted to normal healthy workers. However, all workers are not always healthy. Some elderly workers with COPD, asthma, or the increasing cardiovascular disability with age might become more susceptible to inhaling particulate matter.

We therefore, planned to develop a new animal model of acute bronchiolitis $(\mathrm{Br})$ in rats, and to assess whether these rats are more susceptible to inhaled particles at the levels of TLVs in Japan than their normal controls receiving the same concentrations of particles, or $\mathrm{Br}$ rats kept in clean air.

\section{Materials and Methods}

\section{Methods to develop acute broncho-bronchiolitis in rats}

All animals used in these studies were male SPF rats of Wistar-Jcl strain, purchased from Clea Japan Inc., at 8-weeks of age and were kept in our animal facilities until use. Rats were housed 5 or 6 per stainless wire cage and supplied with sterilized food and water ad libitum. Rats at 10-weeks of age weighing 285-300 $\mathrm{g}$ were moved to the inhalation chambers with volume of $1.2 \mathrm{~m}^{3}$. The chambers were maintained at $24 \pm 0.5^{\circ} \mathrm{C}$ with a relative humidity of $55 \pm$ $5 \%$, air was changed 20 times/h, and a 12-hour light/dark cycle starting at 8:00 a.m. Rats were exposed to aerosols generated from $2 \%$ solution of nickel chloride $\left(\mathrm{NiCl}_{2} \cdot 6 \mathrm{H}_{2} \mathrm{O}\right.$ : $\mathrm{Ni}$ ) by an ultrasonic nebulizer ${ }^{5)}$ for five hours/day starting from 10:00 a.m. to 3:00 p.m., over five days, and they did not receive food and water during five hours daily exposure time. The average concentrations of aerosols were $0.8-0.85$ $\mathrm{mg}$ as $\mathrm{Ni} / \mathrm{m}^{3}$ for the first day, and $0.23-0.25 \mathrm{mg}$ as $\mathrm{Ni} / \mathrm{m}^{3}$ for the second to fifth day. The mass median aerodynamic diameter (MMAD) of the particles was $1.8 \mu \mathrm{m}$ and geometric particle size distribution $(\sigma \mathrm{g})$ was 1.6. These procedures resulted in a stable production of broncho-bronchiolitis $(\mathrm{Br})$ in the shortest time course ever reported ${ }^{6-9)}$.

\section{Exposure methods of $\mathrm{Br}$ rats to particulate matter}

1. Exposure of $\mathrm{Br}$ rats to titanium dioxide $\left(\mathrm{TiO}_{2}: \mathrm{Ti}\right)$ aerosols

Aerosols of Ti were generated from an aqueous suspension of ultrafine $\mathrm{TiO}_{2}$ powder (Idemitsu Titania, Idemitsu Kosan Co, Japan) by an ultrasonic nebulizer ${ }^{5}$. The aerosols consisted of globular aggregates of primary particles ( $20 \mathrm{~nm}$ in diameter, amorphous); and the secondary particles with MMAD of 1.2 $\mu \mathrm{m}$ and $\sigma \mathrm{g}$ was 1.58. Animals were divided into four experimental groups: (1) Br rat + Ti (BT), (2) normal control rat + $\mathrm{Ti}$ (CT), (3) Br control (BC), and (4) normal control (CC). Table 1 shows the experimental design. Inhalation of Ti aerosols started from the following day after 5 days exposure to $\mathrm{Ni}$ (from Day 6-10), at average concentration of $0.95 \pm$ $0.06 \mathrm{mg} / \mathrm{m}^{3}$ for 5 hours/day over 5 days. Five rats/groups were sacrificed at $0 \mathrm{hr}$ and $1,3,7,14$, and 28 days after the last exposure to Ti. All the left lobes of the lung were weighed, dried and analyzed for the tissue concentrations of Ti, and the right lobes were instilled with fixatives and processed for histopathology.

2. Exposure of $\mathrm{Br}$ rats to vanadium pentoxide $\left(\mathrm{V}_{2} \mathrm{O}_{5}: \mathrm{V}\right)$ aerosols

Aerosols of $\mathrm{V}_{2} \mathrm{O}_{5}$ generated from saturated aqueous solution of $\mathrm{V}_{2} \mathrm{O}_{5}$ using an ultrasonic nebulizer. The MMAD of $\mathrm{V}$ particles was $1.1 \mu \mathrm{m}$, and $\sigma \mathrm{g}$ was 1.6. A single inhalation of $\mathrm{V}$ at an average concentration of $2.2 \mathrm{mg} / \mathrm{m}^{3}$ was performed 
Table 2. Experimental design and sampling time after Ni and/or $\mathrm{V}$ exposure

\begin{tabular}{|c|c|c|c|c|c|c|c|c|}
\hline Group Day & D1 & D2 & D3 & D4 & D5 & D6 & D7 & D8 \\
\hline CC: normal control & Air & Air & Air & $\mathrm{CC}$ & & & & \\
\hline \multirow[t]{2}{*}{ CV: normal + V } & Air & Air & Air & V & CV-D5 & & & \\
\hline & Air & Air & Air & Air & V & \begin{tabular}{|l|} 
CV-D6 \\
\end{tabular} & Air & CV-D8 \\
\hline \multirow[t]{2}{*}{ BC: $\mathrm{Br}+\mathrm{Air}$} & $\mathrm{Ni}$ & $\mathrm{Ni}$ & $\mathrm{Ni}$ & $\mathrm{Ni}$ & $\mathrm{Ni}$ & Air & Air & BC-D8 \\
\hline & & & $3 \mathrm{dN}$ & $4 \mathrm{dM}, 4 \mathrm{dN}$ & $5 \mathrm{dM}$ & $6 \mathrm{dM}$ & & \\
\hline \multirow[t]{2}{*}{$\mathbf{B V}: \mathbf{B r}+\mathrm{V}$} & $\mathrm{Ni}$ & $\mathrm{Ni}$ & $\mathrm{Ni}$ & V & BV-D5 & & & \\
\hline & $\mathrm{Ni}$ & $\mathrm{Ni}$ & $\mathrm{Ni}$ & $\mathrm{Ni}$ & V & BV-D6 & Air & BV-D8 \\
\hline
\end{tabular}

Daily exposure time was 10:00 a.m. to 15:00 p.m. N: sampled at $3 \mathrm{hs}$ after the last exposure, at night. M: sampled in the morning, 18 hs after the last exposure. $\mathrm{N}=5$ for BALF, and 2 for histopathology.

for only 5 hours at either Day 4 or Day 5 from the start of Ni exposure. Seven rats/group were sacrificed; 5 rats for bronchoalveolar lavage fluid (BALF) analysis and 2 rats for $\mathrm{V}$ concentrations in the lungs and for histopathology. Table 2 shows the experimental design. For BALF collection, rats were anesthetized by i.p. injection of pentobarbital sodium. After insertion of a catheter in the trachea, $2 \mathrm{ml}$ of blood was collected from the right ventricle and the hilum of the left lung was ligated. Immediately after bleeding through the cut abdominal aorta and vein, BALF was collected after repeated washings of the lung via an inserted tube with sterile saline up and down for 3 times at $25 \mathrm{~cm}$ hydrostatic pressure. Cells in BALF were prepared for differential counting by cytocentrifuge, and stained with MayGrüwald Giemsa.

\section{Histopathology}

The lungs were instilled through the trachea with $10 \%$ neutral formalin and were fixed for 2 days. The right lobes were embedded in paraffin, and serial sections under $2 \mu \mathrm{m}$ thickness were cut and stained with hematoxilin and eosin (HE), alcian blue ( $\mathrm{pH} 2.5$ ) and periodic acid Schiff (AB/ PAS) with or without $\alpha$-amylase digestion.

\section{Statistic analysis}

ANOVA (two-way, one-way) were adopted except for the number of polymorphs in the tissue, in which Kruskal-Wallis test was applied. The criterion for statistical significance was set at $\mathrm{P}<0.05$.

\section{Results}

\section{Profiles of the Br rats and the effects of inhaled PM}

Figure 1 shows the changes in the lung weight and the lung/body weight (L/B) ratios with time after the start of $\mathrm{Ni}$



Fig. 1. Changes in the Lung Weight ratios, and Wet Weight of Left-lobe after Ni Exposure.

The lung weight ratios $\{\mathrm{L} / \mathrm{B}$ expressed as (wet left lung weight/body weight $) \times 1000$ \}, and wet weight of left-lobe $(\mathrm{g})$ after exposure to $\mathrm{NiCl}_{2}$ (Ni). Values are mean \pm standard deviation (SD); $n=5$. Days are from the start of exposure to $\mathrm{Ni}$. $\mathrm{N}$ : sacrificed at night ( 3 hours after the last exposure) and $\mathrm{M}$ : sacrificed in the following morning (18 hours from the last exposure). ${ }^{*} \mathrm{P}<0.05$ vs control, $* * \mathrm{p}<0.01$ vs control. $a=$ significant difference $(\mathrm{p}<0.05)$ between two points connected with each lines.

exposure. Both the wet weight of the left lungs and the L/ $B$ ratios increased significantly in the rats sacrificed at Day 4 morning after 3 days exposure to Ni aerosols. Pathogenesis coincident with those changes showing the submucosal and peri-vascular edema started on Day 3 night accompanied with an increased influx of inflammatory cells in the same areas. Prominent transmigration of both macrophages and neutrophils from the submucosa into the bronchiolar lumen occurred mainly through the enlarged intercellular space of the airway epithelium. In contrast to drastic acute changes in the whole bronchiolar tree such as epithelial hypertrophy, 


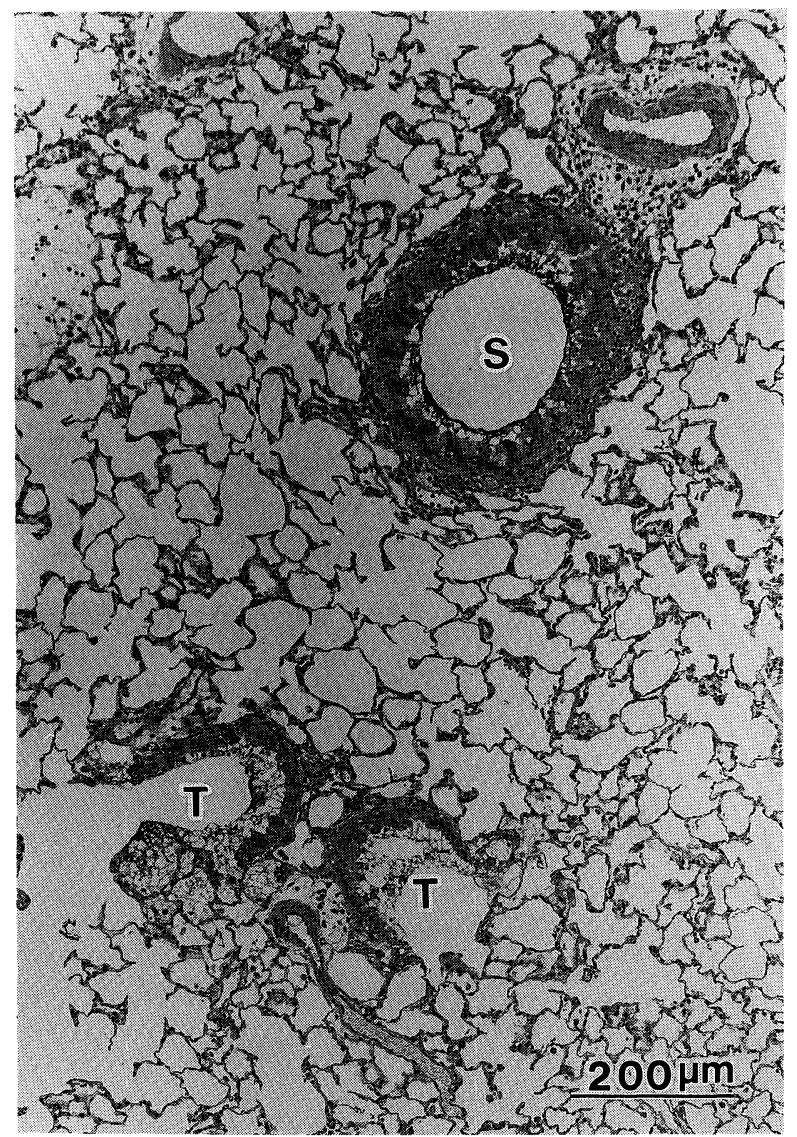

Fig. 2. Light photomicrograph of the lung of a rat exposed to $\mathrm{Ni}$ for 5 days and sacrificed just after the last exposure.

This is a representative morphology of the lung of a rat with $\mathrm{Ni}$-induced bronchiolitis. A small bronchiole and the terminal airways are covered with acidic mucus intermingled with inflammatory cells. Edema and inflammatory cell influx into the submucosal and perivascular interstitium are noted. A slightly enlarged alveoli appeared with their normal structure. $S=$ small bronchiole; $T=$ terminal airways. Stained with alcian blue and PAS.

proliferation, and an increase in the number of goblet cells, the present exposure conditions caused little or a very slight, if any, insult in the alveolar region (Fig. 2). After 5 days exposure to $\mathrm{Ni}$, rats developed acute bronchiolitis judging from the following histopathological criteria: (1) increase in number of secretory cells in the airway epithelium including the terminal bronchioles, (2) abundant mucus production and a shift in the type of glycoprotein present in secretory goblet cells or lumen from a neutral to acidic form, (3) increase in peri-bronchiolar muscle constriction resulting in frequent folding of bronchioli, and (4) increase in submucosal infiltration of inflammatory cells $s^{10}$.

Figure 3 shows the changes in the L/B ratios in control

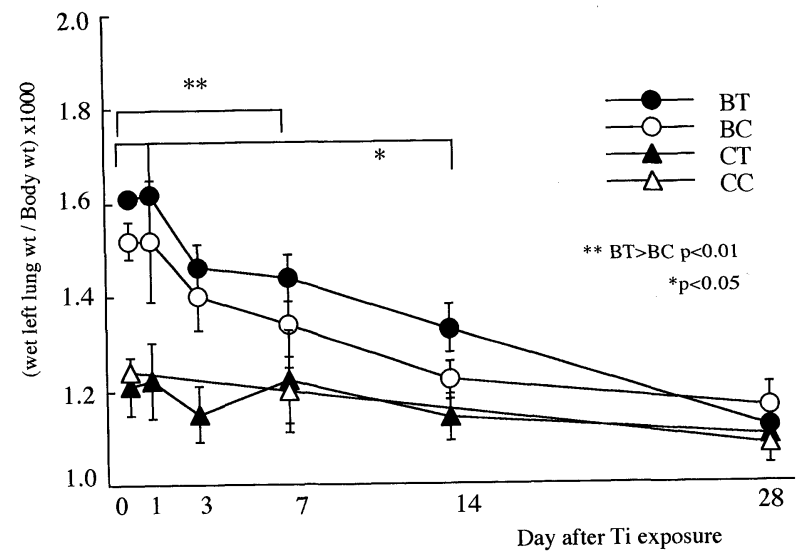

Fig. 3. Changes in the L/B Ratios in Control and Bronciolitic Rats after Exposure to $\mathrm{TiO}_{2}$ (Ti) particles.

Values are mean $\pm S D ; n=5$. The group total values during the first 7 days, and 14 days after the last exposure to $\mathrm{Ti}$ in $\mathrm{BT}$ vs $\mathrm{BC}$ are significantly different $(* * \mathrm{p}<0.01$ and $* \mathrm{P}<0.05$, respectively), and returned to normal levels at Day 28. No difference was found between CC and CT groups.

and $\mathrm{Br}$ rats after exposure to Ti. There was no change in the $\mathrm{L} / \mathrm{B}$ ratios for both $\mathrm{CC}$ and $\mathrm{CT}$ groups during the experimental periods. However, in $\mathrm{Br}$ groups, $\mathrm{BT}$ rats maintained significantly higher ratios than those of $\mathrm{BC}$ rats during 2 weeks after the termination of Ti exposure. Histopathological observations supported that there was no morphological change in CT groups except the appearance of intact alveolar macrophages (AM) with phagocytozed $\mathrm{Ti}$ particles ${ }^{9}$. However, in the BT groups, prominent hypertrophy and hyperplasia of the airway epithelium and abundant infiltration of inflammatory cells in the submucosal interstitia remained while the $\mathrm{BC}$ groups showed less lesions indicating faster recovery than that in BT groups.

Figure 4 shows the changes in the number of $A M$ and neutrophils in BALF after exposure to $\mathrm{Ni}$ and/or $\mathrm{V}$ aerosols. The number of AM in BC groups decreased significantly on Day 5 and 6 compared to normal control or Day 3 and 4 values, then slightly recovered on Day 8 after 3 days in clean air. The number of AM in BV groups on Day 5 and 6 were the same as those of BC groups, and significantly lower than those of $\mathrm{CC}$ and $\mathrm{CV}$ groups. No change was found in the number of $\mathrm{AM}$ in the $\mathrm{CV}$ groups compared to $\mathrm{CC}$ value during the experimental periods. The number of neutrophils increased significantly with time after exposure to $\mathrm{Ni}$ and the maximum value was obtained on Day 4, then decreased gradually with time. No difference was found in the number of neutrophils between $\mathrm{BC}$ and $\mathrm{BV}$ groups, and no increase 


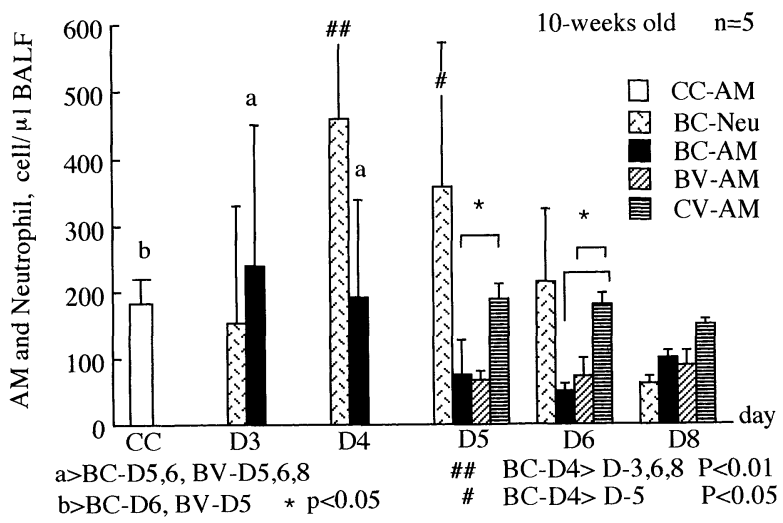

Fig. 4. Changes in the Number of Intact Alveolar Macrophages (AM) and of Neutrophils (Neu) Recovered in Brochoalveolar Lavage Fluid (BALF) after Exposure to $\mathrm{V}_{2} \mathrm{O}_{5}(\mathrm{~V})$ aerosols.

Values are mean $\pm S D ; n=5$. \#\#, \#: Number of Neu at Day (D) 4 in $B C$ groups is higher than those in BC-D3, 6, and 8 (p<0.01), and BC-D5 $(\mathrm{p}<0.05)$. a: Number of AM in BV groups at D5, 6, and 8 is much less than those in $B C$ groups at D5, and $6(p<0.05)$. b: Number of AM in BC-D6 and BV-D5 is less than those in normal control, CC $(\mathrm{p}<0.05)$. No difference was found between $\mathrm{CC}$ and $\mathrm{CV}$ groups during through the experimental periods. No difference was observed in the number of neutrophils between $\mathrm{BC}$ and $\mathrm{BV}$ groups at D5, 6 and 8 (bars not shown).

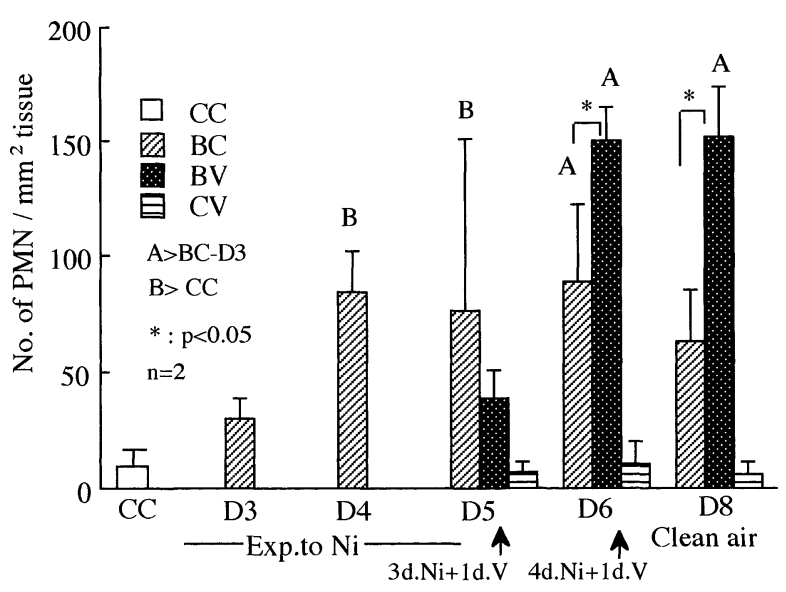

Fig. 5. Number of PMN in the Peri-vascular and Submucosal Interstitium. Number of polymorphonuclear leukocytes (PMN) infiltrated in the perivasucular and submucosal interstitium after exposure to $\mathrm{V}_{2} \mathrm{O}_{5}(\mathrm{~V})$ aerosols.

Values are mean $\pm S D ; n=2$. Total number of cells in the ten equivalent areas from the medium-sized bronchioles were counted and expressed as the number of cells $/ \mathrm{mm}^{2}$ of tissue. Both BC and BV groups show prominent influx of PMN in the interstitium compared to $\mathrm{CC}$ and $\mathrm{CV}$ groups.



Fig. 6. Light photomicrograph of the bronchioles of a $\mathrm{Br}$ rat exposed to $\mathrm{Ni}$ for 4 days, then received a single exposure to $\mathrm{V}$ and sacrificed 3 days after recovery in clean air at Day 8.

There are abundant goblet cells (arrow heads) remained in the airway. Prominent infiltration of inflammatory cells in the submucosal and perivascular interstitium (arrows) is noted. $\mathrm{L}=\mathrm{Large}$ (axial) airway lumen; $M L=$ medium-sized bronchiolar lumen. Stained with hematoxilin and eosin.

observed in the $\mathrm{CV}$ groups as compared to CC (data not shown). On the contrary, significantly greater numbers of polymorphonuclear leukocytes (PMN) infiltrated into the submucosa and perivascular interstitia in the BV groups at Day 6 and 8 as compared to $\mathrm{BC}$ groups, while the values of $\mathrm{CV}$ groups were unchanged and remained at $\mathrm{CC}$ levels (Fig. 5). Figure 6 shows the overall delayed recovery or more progressed tissue lesions in a BV rat sacrificed on Day 8 even after 3 days recovery period in clean air. A prominent goblet cell metaplasia was observed in BV rats as compared to the $\mathrm{BC}$ groups ${ }^{10)}$, and a marked influx of PMN was observed predominantly in the interstitia surrounding the juxtapulmonary vein and venule. 


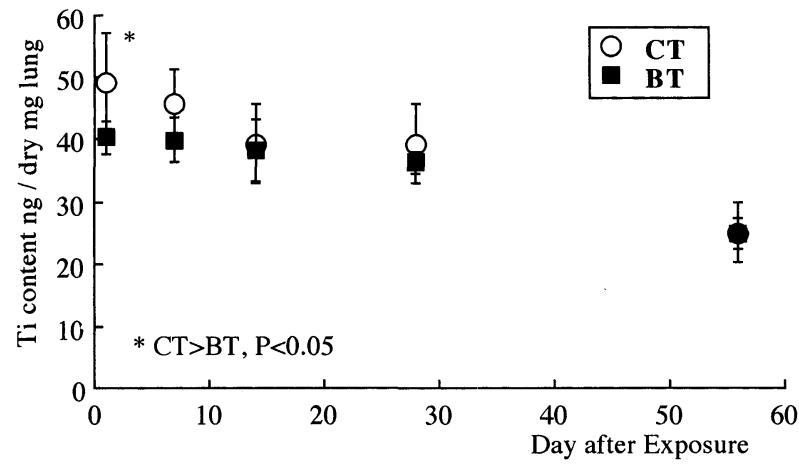

Fig. 7. Concentration of $\mathrm{Ti}$ in the lung.

The lung contents of Ti of rats exposed to Ti for 5 days. Values are mean $\pm S D ; n=5$. Significantly lower Ti concentration in the BT groups vs CT groups was found only in the rats sacrificed just after the last exposure (30 min. to $1 \mathrm{hr}$ ).

\section{Deposition and clearance of $P M$ in the lung of $B r$ rats}

Figures 7 and 8 show the concentrations of Ti and $\mathrm{V}$ in the lungs. In both the BT and BV groups, the concentrations of $\mathrm{Ti}$ and $\mathrm{V}$ were significantly lower than their normal controls, $\mathrm{CT}$ or $\mathrm{CV}$, at $\mathrm{Ohr}$ or 1 day after exposure of particles. However, the initial clearance of the inhaled particles appeared faster in the normal groups for a few days after the termination of exposure, the lung contents of inhaled particles in the $\mathrm{Br}$ and normal groups became almost the same after several days. No difference in Ti contents in the lung was observed in the rats during 2 to 8 weeks after the last exposure to Ti aerosols (Data shown in Fig. 7 was obtained from the comparable, but different experimental groups). The results of BALF cell counts from a repeated experiment showed a significant decrease in the number of AM, but significant increases in neutrophils and lymphocyte in BT groups as compared to those values in CT groups ${ }^{11}$.

A significant difference of $\mathrm{V}$ concentrations was noticed after one day exposure to $\mathrm{V}$ aerosols between the $\mathrm{BV}$ rats exposed to $\mathrm{Ni}$ for 3 days and those exposed for 4 days. Vanadium content in the CV groups at Day 8 was $20 \%$ of the value of that on Day 6, on the other hand, almost $80 \%$ remained in the BV groups on Day 8 as compared to that of Day 6. The only significant effect of $\mathrm{V}$ in $\mathrm{CV}$ groups found in this experiment was an increase in the number of leukocytes in the peripheral blood on Day 8 as compared to non-exposed groups CC (data not shown).

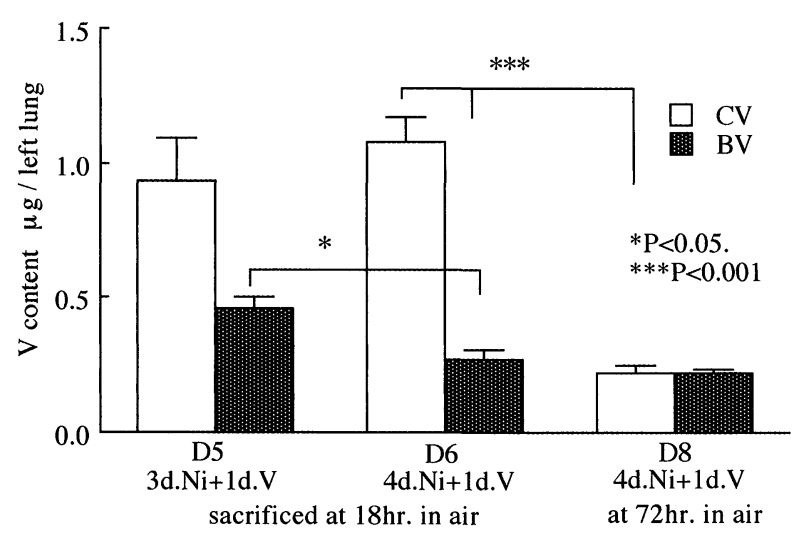

Fig. 8. Concentration of $\mathrm{V}$ in the lung.

The lung contents of $\mathrm{V}$ of rats after a single exposure to $\mathrm{V}$ and sacrificed the following day. Values are mean $\pm S D ; n=2$. Asterisk denotes a significant difference from the groups shown by the respective lines illustrated.

\section{Discussions}

There are a number of animal models of bronchitis or chronic bronchitis (CB). The most widely used is the Reid's model of $\mathrm{CB}$ which is developed by exposing the $\mathrm{SO}_{2}$ gas to animals from a few weeks to a several months ${ }^{6-8,12-14)}$. However, the duration of $\mathrm{CB}$ in this $\mathrm{SO}_{2}$ model is too short to be called chronic because the recovery of the bronchiolar epithelium can occur in a month, without the continuous exposure. Since the present $\mathrm{Br}$ rats induced by $\mathrm{Ni}$ inhalation showed the same morphological changes with those induced by $\mathrm{SO}_{2}$ in that the lesions spread in the whole intrapulmonary airways within a few days, and their recovery time is also one month after the last exposure to $\mathrm{Ni}$ for only five days, we thought that the $\mathrm{Ni}$-induced $\mathrm{Br}$ rats are quick and useful as an acute phase model of bronchiolitis.

The results of exposure of $\mathrm{Br}$ rats to $\mathrm{Ti}$ or $\mathrm{V}$ particles strongly indicate different responses of $\mathrm{Br}$ rats to the inhaled PM as compared with those of the normal healthy rats that have received the same exposure. Noteworthy are significantly lower concentrations of $\mathrm{Ti}$ and $\mathrm{V}$ in the lungs of both in the BT and BV groups than their normal controls, $\mathrm{CT}$ or $\mathrm{CV}$, at $0 \mathrm{hr}$ or 1 day after exposure of particles. Maruyama et al. ${ }^{15)}$ showed that the rats exposed to Ni started higher pulmonary ventilation per minutes from Day 3 to Day 5 , and this state continued until 2 days post exposure, but returned to control level after 3 days post exposure (Day 8 from the start of $\mathrm{Ni}$ exposure). The above result indicates that $\mathrm{Br}$ rats inhaled much more total amounts of $\mathrm{Ti}$ or $\mathrm{V}$, 
nevertheless, the final concentration of either Ti or $\mathrm{V}$ in the lungs of $\mathrm{Br}$ rats at $0 \mathrm{hr}$ or 1 day after the last exposure to $\mathrm{Ti}$, or to $\mathrm{V}$ was lower than that of normal control. At the same time, initial clearance was faster in the $\mathrm{CT}$ or $\mathrm{CV}$ groups than in the Br groups as shown in the Figs. 7 and 8. The above results suggested disabled clearance even for the inhaled insoluble and rather innocuous particles like Ti in the $\mathrm{Br}$ rats during the periods of acute inflammation.

A significant difference of $\mathrm{V}$ concentrations in the $\mathrm{BV}$ rats exposed to $\mathrm{V}$ aerosols at Day 4 or Day 5 that have received exposure of $\mathrm{Ni}$ for 3 or 4 days, may indicate that the degree of airway lesions alters the deposition and clearance pattern of inhaled PM. Since the airway inflammation, constriction of airways, and hypersecretion of mucus was advanced in the rats that had been exposed to $V$ at Day 5 and sacrificed on Day 6. It is plausible that much more inhaled $V$ was deposited in the narrowed airways and the total deposition of $\mathrm{V}$ in the alveolar region was reduced. It is also supported that $\mathrm{Br}$ rats are more susceptible to a single exposure to $\mathrm{V}_{2} \mathrm{O}_{5}$ which caused adverse effects on them, while normal rat showed no detectable changes with the same dose, which was about 28 times $\left(2.2 \mathrm{mg} / \mathrm{m}^{3} \times 5 \mathrm{~h}\right.$ vs $\left.0.05 \mathrm{mg} / \mathrm{m}^{3} \times 8 \mathrm{~h}\right)$ higher than the recommended TLV for $\mathrm{V}_{2} \mathrm{O}_{5}$ in the work place in Japan. Vanadium pentoxide is soluble and absorbed in the lung after several hours, then it is excreted via blood circulation from the kidney. A transient acute toxicity caused by inhaled $\mathrm{V}$ has been well documented ${ }^{16)}$. Knecht et al. reported that exposure of monkeys to $\mathrm{V}_{2} \mathrm{O}_{5}$ at $5 \mathrm{mg} / \mathrm{m}^{3}$ caused air-flow limitation but not at $0.5 \mathrm{mg} \mathrm{V} \mathrm{O}_{5} / \mathrm{m}^{3}$, under conditions that do not produce detectable changes in parencymal function. Their results of the BAL performed just after the lung function test at 1day after inhalation showed about a two-fold increase in total cells due mainly to a dramatic increase in the absolute number of polymorphonuclear leukocytes (PMN), despite a slight decrease in the number of $A M$ recovered from $B A L F^{17}$. Although the concentration of $\mathrm{V}_{2} \mathrm{O}_{5} / \mathrm{m}^{3}$ in the present study was less than half of their dose, and BAL data showed no difference in the number of both AM and PMN between CC and CV groups. However, the number of AM significantly decreased at Day 5 and Day 6 in the BV groups as compared to $\mathrm{CC}$ or $\mathrm{CV}$ values. The delayed clearance of $\mathrm{V}_{2} \mathrm{O}_{5}$ in the $\mathrm{BV}$ groups might be attributable to both the reduced number of $\mathrm{AM}$ and the disability of AM following exposure to soluble Ni. Vanadium pentoxide is only slightly soluble in water, and the present data suggest that inhaled $V$ in the present conditions caused no adverse effect both on AM and parencymal tissue during 24 hours post exposure, since there was no significant difference observed in the number of AM and PMN between $\mathrm{BV}$ and $\mathrm{BC}$ groups. On the other hand, the significant accumulation of PMN in the submucosa or perivascular interstitium in $\mathrm{BV}$ groups at Day 8 than that of $\mathrm{BC}$ groups suggests that the adverse effect of $\mathrm{V}_{2} \mathrm{O}_{5}$ appeared after solubilization of $\mathrm{V}$ particles in the alveoli and then a transport via blood stream, because the number of peripheral blood leukocytes in the CV groups also increased on Day 8 without any extra accumulation of PMN in the interstitia.

No direct evidence is available regarding the possibility that the residual $\mathrm{Ni}$ in the lungs of $\mathrm{Br}$ rats may interact with the inhaled PM and interfere with the clearance of inhaled $\mathrm{PM}$. The residual concentration of highly soluble $\mathrm{NiCl}_{2}$ in the lung after 5 days exposure to develop bronchiolitis was about $3 \mu \mathrm{g}$, and $1 \mu \mathrm{g} / \mathrm{dry} \mathrm{g}$ lung, at Day 1 and 4 post exposure, respectively (unpublished data). Because of the highly hygroscopic nature of inhaled $\mathrm{NiCl}_{2}$ aerosols, it is plausible that most of the inhaled $\mathrm{Ni}$ was deposited on the surface of mucous layer of the airways and directly absorbed by the airway epithelium and only a minor part was deposited in the alveoli and being absorbed by alveolar epithelium or phagocytozed by AM as Ni-surfactant complex. As we had chosen carefully the doses of exposing $\mathrm{Ni}$ that cause minimal injury to the alveoli according to the histopathological observations and also there was no exfoliation of the airway epithelium found on Day 5 when bronchiolitis has been developed, the AM may be subjected to the primary target of the residual Ni. Both the reduced number and damage of AM may result in decrease of initial clearance of the inhaled PM. Disturbance of clearance at Day 8 (Fig. 8) as reflected in $80 \%$ of the deposited $\mathrm{V}$ after 72 hours post inhalation supports the above hypothesis. It has been well known that any kinds of Ni compounds either highly soluble or insoluble cause injury to $\mathrm{AM}^{18,19)}$. Bingham et $a l .{ }^{20)}$ reported that an increase of $\mathrm{AM}$ after inhalation exposure to $\mathrm{NiCl}_{2}(0.1 \mathrm{mg} /$ $\left.\mathrm{m}^{3}\right) 8 \mathrm{hr} /$ day, 5 days/week for 18 days was very low as compared to the prominent increase after the inhalation of the same dose of an insoluble $\mathrm{Ni}$ compound, nickel oxide (NiO). However, as Benson et al. has reported ${ }^{18)}$, we should keep in mind that the species differences exist in the sensitivity of canine and rat AM to Ni. For example, the $\operatorname{dog} \mathrm{AM}$ was at least 10 times more sensitive than was the rat AM.

The above results suggest that $\mathrm{Br}$ rats are more susceptible to inhaled particles than normal rats. Therefore, our Niinduced $\mathrm{Br}$ model is useful to assess the differences in toxicity of any PM in a pre-existing inflammation of the lung. Finally, the concentrations of PM lower than the recommended 
threshold limit values in Japan, which have no harmful effects on normal lungs, may not always be safe in the case of preexisting lung disease.

\section{Acknowledgements}

This is a part of research project entitled "Development of a new method to assess the biological effects of exposure to environmental pollutants using model animals with respiratory disease", which was supported in part by the Environmental Agency, Japan.

A part of this research was presented in the fifteenth symposium on aerosol science and technology Japan (August 20-22, 1998, Saitama, Japan) and the first Korea-Japan joint symposium of occupational lung disease (August 24-25, 1998, Seoul, Korea).

\section{References}

1) Utell MJ, Frampton W (1995) Particles and mortality: a clinical perspective. Inh Toxicol 7, 645-55.

2) Samet JM, Zeger SL, Berhane K (1995) The association of mortality and particle air pollution. The phase I report of the particle epidemiology evaluation project.

3) McClellan RO, Miller FJ (1997) An overview of EPA's proposed revision of the particulate matter standard. CIIT Activities 17 (4), 1-21.

4) Utell MJ, Drew R (1998) Summary of the workshop on clinical studies and particulate matter. Inhal Tox 10, 625-38.

5) Serita F (1997) Development of a new aerosol generating cell with an ultrasonic nebulizer. Ind Health 35, 433-9.

6) Lamb D, Reid L (1968) Mitotic rates, goblet cell increase and histochemical changes in mucus in rat bronchial epithelium during exposure to sulphur dioxide. J Pathol Bacteriol 96, 97-111.

7) Jones R, Reid L (1978) Secretory cell hyperplasia and modification of intracellular glycoprotein in rat airways induced by short periods of exposure to tobacco smoke, and the effect of the anti-inflammatory agent phenylmethyloxadiazole. Lab Invest 39, 41-9.

8) Reid L, Jones R (1983) Experimental Chronic Bronchitis. Int Rev Exp Pathol 24, 335-82.

9) Kyono H, Serita F, Maruyama R, Kubota H, Toya T (1995) Cell dynamic analysis in a course of development for bronchiolitis in rats exposed to $\mathrm{NiCl}_{2}$. Int Cong ToxVII Abstracts 20-p-8.

10) Kyono $H$, Serita $F$, Arito $H$, Maruyama $R$, Takahashi M, Kubota H, Toya T, Homma K (1994) Development of a new method to assess the biological effects of exposure to environmental pollutants using model animals with respiratory disease. Env Res II, Japan (74) 1-22 (in Japanese).

11) Kyono H, Serita F, Kubota H, Toya T, Nakakita M, Yamuchi Y, Ohta H, Seki Y, Ishihara Y, Kagawa J, Maruyama R (1996) Development of a new method to assess the biological effects of exposure to environmental pollutants using model animals with respiratory disease. Env Res II, Japan (76) 1-44 (in Japanese).

12) Chakrin LW, Saunders LZ (1974) Experimental chronic bronchitis. Pathology in the dog. Lab Invest 30, 14554.

13) Drazen JM, O'Cain CF, Ingram RH. Jr. (1982) Experimental induction of chronic bronchitis in dogs. Effects on airway obstruction and responsiveness. Am Rev Respir Dis 126,75-9.

14) Seltzer J, Scanlon PD, Drazen JM, Ingram RH Jr., Reid L (1984) Morphologic correlation of physiologic changes caused by $\mathrm{SO}_{2}$-induced bronchitis in dogs. Am Rev Respir Dis 129, 790-7.

15) Maruyama R, Kyono H, Serita F, Toya T, Fukuda $Y$ (1995) A pathogenesis of broncho-bronchiolitis model rats. Proc. $36^{\text {th }}$ annual meet Jap Soc Air Pollution, Tokyo p 311 (Abstract in Japanese).

16) KiViluoto $M$ (1980) Observations on the lungs of vanadium workers. Br J Ind Med 37, 363-6.

17) Kneck EA, Moorman WJ, Clark JC, Lynch DW, Lewis TR (1985) Pulmonary effects of acute vanadium pentoxide inhalation in monkeys. Am Rev Respir Dis 132, 1181-5.

18) Benson JM, Henderson RF, McClellan RO, Hanson RL, Rebar AH (1986) Comparative acute toxicity of four nickel compounds to F344 rat lung. Fund Appl Toxicol 7, 340-7.

19) Adkins B. Jr., Richards JH, Gardner DE (1979) Enhancement of experimental respiratory infection following nickel inhalation. Env Res 20, 33-42.

20) Bingham E, Barkley $W$, Zerwas $M$, Stemmer K, Taylor P (1972) Response of alveolar macrophages to metals. I. Inhalation of lead and nickel. Arch Environ Health 25, 406-14. 